\title{
The Use of Chromogenic Reference Substrates for the Kinetic Analysis of Penicillin Acylases ${ }^{1}$
}

\author{
Wynand B. L. Alkema, René Floris, and Dick B. J anssen ${ }^{2}$ \\ Department of Biochemistry, Groningen Biomolecular Sciences and Biotechnol ogy Institute, University of Groningen, \\ Nijenborgh 4, 9747 AG Groningen, The Netherlands
}

Received April 12, 1999

Determination of kinetic parameters of penicillin acylases for phenylacetylated compounds is complicated due to the low $K_{m}$ values for these substrates, the lack of a spectroscopic signal, and the strong product inhibition by phenylacetic acid. To overcome these difficulties, a spectrophotometric method was developed, with which kinetic parameters could be determined by measuring the effects on the hydrolysis of the chromogenic reference substrate 2-nitro-5-[(phenylacetyl)amino]benzoic acid (NIPAB). To that end, spectrophotometric progress curves with NIPAB in the absence and presence of the phenylacetylated substrates and their products were measured and analyzed by numerical fitting to the appropriate equations for competing substrates with product inhibition. This analysis yielded kinetic constants for phenylacetylated substrates such as penicillin G, which are in close agreement with those obtained in independent initial velocity experiments. Using NIPAB analogs with lower $\mathbf{k}_{\text {cat }} / K_{m}$ values, kinetic parameters for the hydrolysis of cephalexin and penicillin V were determined. This method was suitable for determining the kinetic constants of penicillin acylases in periplasmic extracts from Escherichia coli, Alcaligenes faecalis, and Kl uyvera citrophila. The use of chromogenic reference substrates thus appears to be a rapid and reliable method for determining kinetic constants with various substrates and enzymes. ๑ 1999 Academic Press

Penicillin acylase of Escherichia coli ATCC 11105 (EC 3.5.1.11) catalyzes the hydrolysis of penicillin $\mathrm{G}$ to

\footnotetext{
${ }^{1}$ This work was financially supported by Chemferm and by the Dutch Ministry of Economic Affairs.

${ }^{2}$ To whom correspondence should be addressed. Fax: +31-503634165. E-mail: d.b.janssen@chem.rug.nl
}

phenylacetic acid and 6-aminopenicillanic acid (6APA), ${ }^{3}$ which is a building block in the synthesis of semi-synthetic $\beta$-lactam antibiotics (1). Since the enzyme can also be applied in the condensation reaction with a variety of acyl donors, penicillin acylase can potentially be used for biocatalytic synthesis of various semisynthetic antibiotics, which are of pharmaceutical importance. For efficient screening of enzymes with improved catalytic properties, it is necessary to use a rapid and reliable method for the determination of the kinetic constants for penicillin $G$ and other $\beta$-lactam compounds. These parameters can in principle be determined with several methods. The 6-APA produced during hydrolysis of penicillin $G$ can be detected directly using HPLC methods, by fluorescence measurements after reaction with fluorescamine (2), or by colorimetric measurements after derivatization with 4-(dimethylamino)benzal dehyde (3). The released phenylacetic acid can also be monitored by acid/base titration (4).

However, these methods are time-consuming and, except for titration methods, require quenching of the reaction prior to analysis. Furthermore, the measurements are complicated by the chemical instability of the $\beta$-lactam compounds $(5,6)$, and the low sensitivity of some of these methods complicates accurate determination of the low $K_{m}$ values typical for phenylacetylated substrates. Moreover, the classical steady-state method of measuring initial rates is prone to severe error because of the strong product inhibition by phenylacetic acid. Due to these complications, $K_{m}$ values for penicillin $G$ and $K_{i}$ values for phenylacetic acid of

\footnotetext{
${ }^{3}$ Abbreviations used: NIPAB, 2-nitro-5-[(phenylacetyl)amino]benzoic acid; NIPGB, D-2-nitro-5-[(phenylglycyl)amino]benzoic acid; NIPOAB, 2-nitro-5-[(phenoxyacetyl)amino]benzoic acid; 6-APA, 6-aminopenicillanic acid; 7-ADCA, 7-aminodesacetoxycephalosporanic acid; PMSF, phenylmethylsulfonyl fluoride.
} 


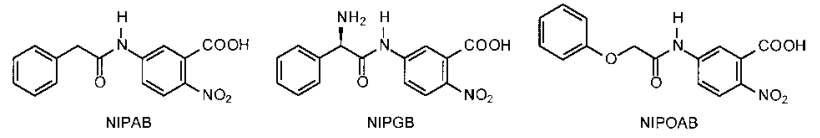

FIG. 1. Chromogenic reference substrates used to determine the kinetics of invisible substrates.

penicillin acylase of $\mathrm{E}$. coli have been reported, which differ by several orders of magnitude (3, 7-10).

To overcome these problems we devel oped a spectrophotometric method for the direct determination of the kinetic constants for invisible substrates, i.e., substrates, such as penicillin $G$, which do not display a significant change in absorbance upon conversion. The method is based on measuring the effect of the invisible substrate on the conversion of a spectrophotometric reference compound.

When two substrates are converted by an enzyme at the same active site and follow Michaelis-Menten kinetics, the substrates competitively inhibit the conversion of each other (11). The conversion of both substrates can be described by rate Eq. [1],

$$
\frac{\mathrm{d}\left[\mathrm{S}_{1}\right]}{\mathrm{dt}}=-\frac{\mathrm{V}_{\max \mathrm{S}_{1}}\left[\mathrm{~S}_{1}\right]}{\mathrm{K}_{\mathrm{mS}_{1}}\left(1+\frac{\left[\mathrm{S}_{2}\right]}{\mathrm{K}_{\mathrm{mS}_{2}}}\right)+\left[\mathrm{S}_{1}\right]},
$$

where $\mathrm{V}_{\text {maxs1 }}, \mathrm{K}_{\mathrm{ms} 1}$, and $\mathrm{K}_{\mathrm{ms} 2}$ are the kinetic parameters of the enzyme. From this equation it follows that if the kinetics of the first substrate are known, the kinetic parameters of the enzyme for the second substrate can be determined by analyzing the effect of the second substrate on the kinetics of conversion of the first substrate. As a chromogenic substrate we used 2-nitro-5[(phenylacetyl)amino]benzoic acid (NIPAB) (Fig. 1) and analogs thereof, of which the hydrolysis causes an increase in absorbance at $405 \mathrm{~nm}$ due to the liberation of 5-amino-2-nitrobenzoic acid (8). Using numerical integration of the relevant differential equations for product formation, accurate estimates for various invisible substrates could be obtained.

\section{METHODS}

\section{Growth of Bacteria and Enzyme Purification}

Strains of E. coli HB101 carrying the cloned genes of $E$. coli and Alcaligenes faecalis penicillin acylase were provided by Dr. J.-M. van der Laan (Gist brocades, Delft, The Netherlands). Cells were grown in LB medium (12) at $17^{\circ} \mathrm{C}$ and rotary shaking at $150 \mathrm{rpm}$. Cells were harvested in the late exponential phase by centrifugation at $5000 \mathrm{~g}$ for $10 \mathrm{~min}$. Periplasmic extract was prepared by resuspending the cells in $\frac{1}{10}$ of the original culture volume of ice-cold osmotic shock buffer
A (20\% sucrose, $100 \mathrm{mM}$ Tris $\cdot \mathrm{HCl}, 10 \mathrm{mM}$ EDTA, pH 8.0) and centrifuged at $5000 \mathrm{~g}$ for $10 \mathrm{~min}$. Subsequently, the cells were resuspended in $\frac{1}{10}$ of the original culture volume of ice-cold $1 \mathrm{mM}$ EDTA and centrifuged at $5000 \mathrm{~g}$ for $10 \mathrm{~min}$. Potassium phosphate buffer (1 M, $\mathrm{pH}$ 7.0) was added to the supernatant to a final concentration of $50 \mathrm{mM}$. The periplasmic extracts were then stored at $-20^{\circ} \mathrm{C}$. For further purification, $\left(\mathrm{NH}_{4}\right)_{2} \mathrm{SO}_{4}$ was added to the periplasmic extract to a final concentration of $1.5 \mathrm{M}$. The sample was loaded on a Resource Phe (Pharmacia) column and eluted with a linear gradient of 1.5 to $0 \mathrm{M}\left(\mathrm{NH}_{4}\right)_{2} \mathrm{SO}_{4}$ in $20 \mathrm{mM}$ potassium phosphate buffer of $\mathrm{pH}$ 7.0. The penicillin acylase of $\mathrm{E}$. coli eluted at a concentration of $1 \mathrm{M}$ $\left(\mathrm{NH}_{4}\right)_{2} \mathrm{SO}_{4}$. Fractions containing the active enzyme were pooled and using ultrafiltration (Amicon ultrafiltration cell, with a YM 30 filter), the buffer system was replaced with $50 \mathrm{mM}$ potassium phosphate, $\mathrm{pH}$ 7.0, 5\% glycerol.

Penicillin acylase of Kluyvera citrophila ATCC 21285 was obtained by growing $\mathrm{K}$. citrophila in $\mathrm{BHI}$ medium at $30^{\circ} \mathrm{C}$ and performing the osmotic shock as described above.

In each case, the amount of active enzyme was determined by titration with phenylmethylsulfonyl fluoride (PMSF). Stock concentrations of $10 \mathrm{mM}$ PMSF were made in acetonitrile. Penicillin acylase was incubated at $\mathrm{pH} 7.0$ for $10 \mathrm{~min}$ at room temperature with various concentrations of freshly diluted PMSF in 50 $\mathrm{mM}$ phosphate buffer. Residual activity was measured with NIPAB as the substrate.

\section{Determination of Kinetic Parameters}

When NIPAB and penicillin G are present in a reaction mixture, the hydrolysis of NIPAB by penicillin acylase is described by Eq. [2],

$$
\begin{aligned}
& \frac{\mathrm{d}[\mathrm{NIPAB}]}{\mathrm{dt}} \\
& =-\frac{\mathrm{k}_{\mathrm{cat}}^{\mathrm{NIPAB}}\left[\mathrm{E}_{0}\right][\mathrm{NIPAB}]}{\mathrm{K}_{\mathrm{m}}^{\mathrm{NIPAB}}\left(1+\frac{[\mathrm{PenG}]}{\mathrm{K}_{\mathrm{m}}^{\text {PenG }}}+\frac{[\mathrm{PAA}]}{\mathrm{K}_{\mathrm{i}}^{\text {PAA }}}+\frac{[\mathrm{APA}]}{\left.\mathrm{K}_{\mathrm{i}}^{\mathrm{APA}}\right)}\right.},
\end{aligned}
$$

where $\mathrm{K}_{\mathrm{m}}^{\mathrm{NIPAB}}$ and $\mathrm{K}_{\mathrm{m}}^{\text {PenG }}$ denote the affinity constants for NIPAB and penicillin G, respectively, and $k_{c a t}^{N I P A B}$ is the catalytic constant for NIPAB. Since penicillin acylase is inhibited competitively by the products of penicillin G and NIPAB hydrolysis (4, Alkema, manuscript in preparation), inhibition constants for phenylacetic acid $\left(\mathrm{K}_{i}^{\mathrm{PAA}}\right)$ and 6-APA $\left(\mathrm{K}_{i}^{\mathrm{APA}}\right)$ are included. Similarly, the conversion of penicillin $\mathrm{G}$ can be described by 


$$
\begin{aligned}
& \mathrm{d} \text { [PenG] } \\
& \mathrm{dt} \\
& =-\frac{\mathrm{K}_{\mathrm{cat}}^{\text {PenG }}\left[\mathrm{E}_{0}\right][\mathrm{PenG}]}{\mathrm{K}_{\mathrm{m}}^{\text {PenG }}\left(1+\frac{[\mathrm{NIPAB}]}{\mathrm{K}_{\mathrm{m}}^{\mathrm{NIPAB}}}+\frac{[\mathrm{PAA}]}{\mathrm{K}_{\mathrm{i}}^{\mathrm{PAA}}}+\frac{[\mathrm{APA}]}{\left.\mathrm{K}_{\mathrm{i}}^{\text {APA }}\right)}\right.}+,
\end{aligned}
$$

where $\mathrm{k}_{\text {cat }}^{\text {PenG }}$ is the catalytic constant for penicillin G. Phenylacetic acid is produced in both reactions, so the concentration of phenylacetic acid is described by:

$$
\begin{aligned}
& {[P A A]_{t}=[P A A]_{t=0}+}\left([\text { NIPAB }]_{t=0}-[\text { NIPAB }]_{t}\right) \\
&+\left([\text { PenG }]_{t=0}-[\text { PenG }]_{t}\right)
\end{aligned}
$$

and 6-APA is produced by the hydrolysis of penicillin $G$, so the concentration of 6-APA is described by:

$$
[\mathrm{APA}]_{\mathrm{t}}=[\mathrm{APA}]_{\mathrm{t}=0}+\left([\mathrm{PenG}]_{\mathrm{t}=0}-[\mathrm{PenG}]_{\mathrm{t}}\right)
$$

The hydrolysis of NIPAB is monitored by measuring the increase in absorbance at $405 \mathrm{~nm}$ caused by the liberation of 5-amino-2-nitrobenzoic acid. So

$$
\mathrm{ABS}_{\mathrm{t}}=\epsilon \mathrm{d}\left([\mathrm{NIPAB}]_{\mathrm{t}=0}-[\mathrm{NIPAB}]_{\mathrm{t}}\right),
$$

where $\epsilon$ is the molar extinction coefficient of 5-amino2-nitrobenzoic acid which is $9.09 \mathrm{mM}^{-1} \cdot \mathrm{cm}^{-1}$ at $\mathrm{pH} 7.0$ (8) and $d$ is the length of the optical path.

Enzymatic hydrolysis of chromogenic substrates was followed continuously by monitoring the absorbance at $405 \mathrm{~nm}$ with a Perkin-EImer Lambda Bio 40 spectrometer. All conversions were carried out at $30^{\circ} \mathrm{C}$ in 50 $\mathrm{mM}$ potassium phosphate buffer, $\mathrm{pH}$ 7.0.

Data were analyzed using the program Scientist (Micromath Inc., version 2.0). Data sets from independent experiments were fitted simultaneously, using the least-squares fitting procedure implemented in the program. In this fitting procedure parameters with a known value, e.g., substrate and enzyme concentrations, were fixed. Unknown kinetic parameters were set as fitting parameters and their values were found by fitting the system of differential equations to the experimentally obtained absorbance data sets. Fitting procedures were run with different initial estimates of fitting parameters to obtain an indication of whether unique solutions were found for the fitting parameters. The goodness of fit and the information content of the data were also checked by inspecting the standard deviations of the parameter values and the correlation between the fitting parameters, using the Statistics procedure implemented in the Scientist program.

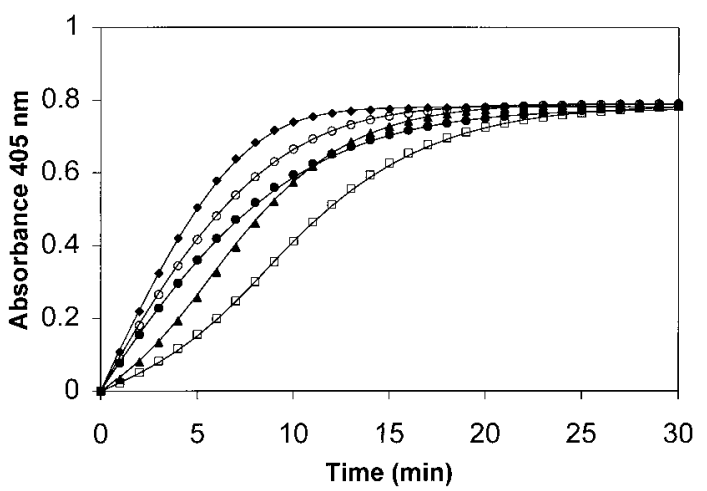

FIG. 2. Progress curves of NIPAB hydrolysis in the presence of different concentrations of phenylacetic acid and penicillin G. Symbols: Hydrolysis of $86 \mu \mathrm{M}$ NIPAB $(\diamond)$ without a second substrate, $(\bigcirc)$ with $100 \mu \mathrm{M}$ phenylacetic acid, (•) with $200 \mu \mathrm{M}$ phenylacetic acid, (A) with $100 \mu \mathrm{M}$ penicillin $\mathrm{G}$, and $(\square)$ with $200 \mu \mathrm{M}$ penicillin $\mathrm{G}$. Symbols denote experimental data; the line shows the fit with the following parameters: $\mathrm{k}_{\mathrm{cat}}^{\mathrm{NIPAB}}=16.2 \mathrm{~s}^{-1}, \mathrm{~K}_{\mathrm{m}}^{\mathrm{NIPAB}}=11.3 \mu \mathrm{M}, \mathrm{K}_{\mathrm{i}}^{\mathrm{PAA}}=$ $57.3 \mu \mathrm{M}, \mathrm{k}_{\mathrm{cat}}^{\text {PenG }}=42 \mathrm{~s}^{-1}, \mathrm{~K}_{\mathrm{m}}^{\text {PenG }}=6 \mu \mathrm{M}$.

\section{Chemicals}

NIPAB was purchased from Sigma Chemical Co. D-2-Nitro-5-[(phenylglycyl)amino]benzoic acid (NIPGB) was purchased from Syncom (Groningen, The Netherlands). 2-Nitro-5-[(phenoxyacetyl)amino]benzoic acid (NIPOAB) was synthesized as described (13). Penicillin $G$, penicillin $V$, and cephalexin were a gift of Gist brocades. PMSF was from Boehringer-Mannheim. Phenylacetic acid methyl ester was from Aldrich.

\section{RESULTS}

Kinetics of NIPAB Hydrolysis and Phenylacetic Acid Inhibition

To investigate the possibility of using progress curves for analyzing the kinetics of the conversion of an invisible substrate, the kinetic parameters of NIPAB conversion were first determined using purified penicillin acylase. Reactions were carried out with NIPAB as the sole substrate and phenylacetic acid was added at different concentrations to obtain the inhibition constant (Fig. 2). Phenylacetic acid had a significant effect on the shape of the progress curves, and product inhibition thus must be included in the model. The progress curves were fitted to equations described above using $\mathrm{K}_{\mathrm{cat}}^{\mathrm{NIPAB}}, \mathrm{K}_{\mathrm{m}}^{\mathrm{NIPAB}}$, and $\mathrm{K}_{\mathrm{i}}^{\mathrm{PAA}}$ as fitting parameters to obtain values for the kinetic constants for NIPAB hydrolysis (Table 1 ).

The values for $\mathrm{k}_{\text {cat }}$ and $\mathrm{K}_{\mathrm{m}}$ of NIPAB hydrolysis and the inhibition constant for phenylacetic acid were also determined using classical initial rates measurements at various NIPAB concentrations and varying phenylacetic acid concentrations (Table 1). In these experiments care was taken that the concentrations of phe- 
TABLE 1

Kinetic Parameters of E. col i Penicillin Acylase for NIPAB Hydrolysis and the Inhibition Constant for Phenylacetic Acid Obtained with Progress Curve Analysis

\begin{tabular}{|c|c|c|c|}
\hline Constant & Fitted value & $\begin{array}{l}\text { Independent } \\
\text { experiments }\end{array}$ & $\begin{array}{l}\text { Literature } \\
\text { values }^{\mathrm{a}}\end{array}$ \\
\hline $\mathrm{K}_{\mathrm{cat}}^{\mathrm{NIPAB}}\left(\mathrm{s}^{-1}\right)$ & $16.2 \pm 0.2$ & 13 & $15-20$ \\
\hline $\mathrm{K}_{m}^{\text {NIPAB }}(\mu \mathrm{M})$ & $11.3 \pm 0.8$ & 11 & $15-25$ \\
\hline $\mathrm{K}_{i}^{\text {PAA }}(\mu \mathrm{M})$ & $57.3 \pm 0.8$ & 68 & $50-5000$ \\
\hline
\end{tabular}

${ }^{\text {a }}$ Data were taken from Refs. (8-10) and (14).

nylacetic acid produced by hydrolysis of NIPAB were never higher than $10 \%$ of the $K_{i}$ value. The values obtained from progress curves for the hydrolysis of NIPAB were in good agreement with the values obtained with the initial rate experiments and with data reported by Kutzbach and Rauenbusch (8) and Kasche et al. (14). For phenylacetic acid, inhibition constants ranging from 0.05 to $5 \mathrm{mM}$ have been reported $(3,7,8$, 10). However, the $K_{m}$ and $K_{i}$ values for other phenylacetylated compounds are all in the range of 10 to 200 $\mu \mathrm{M}(9,14)$, which indicates that the $K_{i}$ value of $70 \mu \mathrm{M}$ for phenylacetic acid obtained in these experiments is correct. These results show that accurate kinetic constants were obtained by analysis of progress curves (Table 1).

\section{Kinetic Constants for Invisible Phenylacetylated Compounds}

The kinetic parameters of hydrolysis of penicillin $G$ were determined by studying the effect of penicillin $G$ on NIPAB hydrolysis. Various concentrations of penicillin $G$ were added to reaction mixtures containing NIPAB as the chromogenic reference substrate and the reaction progress curves were recorded (Fig. 2). The first part of the progress curve showed that inhibition of NIPAB hydrolysis occurred. During the course of the reaction the rate gradually increased to a point at which it decreased again due to the depletion of NIPAB. The S shape of the curves indicates that penicillin $\mathrm{G}$ is converted and the weaker inhibitor phenylacetic acid is produced.

When phenylacetic acid methyl ester was used as the invisible substrate, a gradual decrease of the rate of hydrolysis was observed (Fig. 3). At the start of the reaction, $500 \mu \mathrm{M}$ phenylacetic acid methyl ester and $200 \mu \mathrm{M}$ phenylacetic acid caused the same degree of inhibition of NIPAB hydrolysis, whereas $200 \mu \mathrm{M}$ phenylacetic acid methyl ester showed less inhibition than $200 \mu \mathrm{M}$ phenylacetic acid. During conversion, the rate of NIPAB hydrolysis decreased faster in the reaction mixtures with phenylacetic acid methyl ester than that in the mixture with phenylacetic acid. This indicates

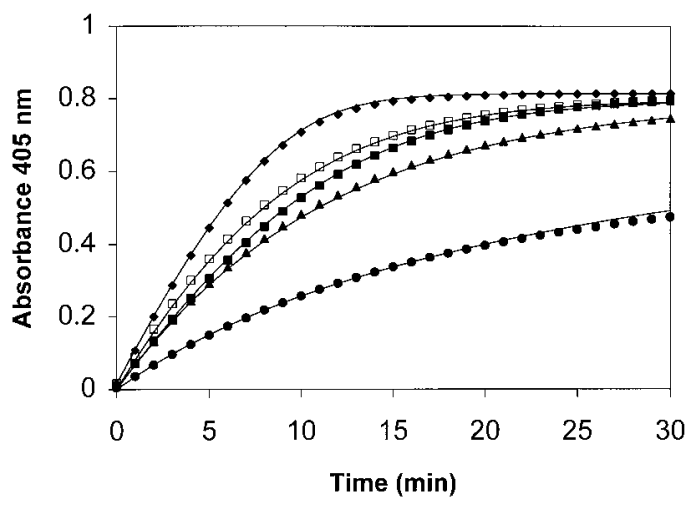

FIG. 3. Progress curves of NIPAB hydrolysis in the presence of different concentrations of phenylacetic acid and phenylacetic acid methyl ester. Symbols: Hydrolysis of $86 \mu \mathrm{M}$ NIPAB $(\diamond)$ without a second substrate, ( $\square$ ) with $200 \mu \mathrm{M}$ phenylacetic acid, ( $\square$ ) with 200 $\mu \mathrm{M}$ phenylacetic acid methyl ester, (A) with $500 \mu \mathrm{M}$ phenylacetic acid methyl ester, and (0) with $2000 \mu \mathrm{M}$ phenylacetic acid methyl ester. Symbols denote experimental data, the line shows the fit with the following parameters: $\mathrm{k}_{\mathrm{cat}}^{\mathrm{NIPAB}}=16.2 \mathrm{~s}^{-1}, \mathrm{~K}_{\mathrm{m}}^{\mathrm{NIPAB}}=11.3 \mu \mathrm{M}, \mathrm{K}_{\mathrm{i}}^{\mathrm{PAA}}=$ $57.3 \mu \mathrm{M}, \mathrm{k}_{\text {cat }}^{\text {phenylacetic acid methyl ester }}=190 \mathrm{~s}^{-1}, \mathrm{~K}_{\mathrm{m}}^{\text {phenylacetic acid methyl ester }}=156$ $\mu \mathrm{M}$.

that penicillin acylase has a higher affinity for phenylacetic acid than for phenylacetic acid methyl ester and that the latter compound is converted to the stronger inhibitor phenylacetic acid. When phenylacetamide was used as an invisible substrate, the same effect was observed, i.e., conversion of phenylacetamide to the stronger inhibitor phenylacetic acid (data not shown).

The kinetic constants obtained after fitting of the progress curves are in agreement with these observations (Table 2). The inhibition by 6-APA was ignored in this fitting procedure because the $K_{i}$ of 6-APA is about three orders of magnitude higher ( $100 \mathrm{mM}$ ) (Alkema, manuscript in preparation) than the concentrations produced during the conversion of $200 \mu \mathrm{M}$ penicillin G. From Table 2 it can be concluded that penicillin acylase indeed has the lowest $K_{m}$ for penicillin $G$ and that the $\mathrm{K}_{i}$ for phenylacetic acid is lower than the $\mathrm{K}_{m}$ values for phenylacetic acid methyl ester and phenylacetamide.

\section{Kinetic Constants of Other Acylases}

To test whether the method of progress curve analysis is accurate enough to discriminate between acy-

TABLE 2

Kinetic Parameters of E. coli Penicillin Acylase Obtained with Progress Curve Analysis for Invisible Substrates

\begin{tabular}{lrrrr}
\hline \multicolumn{1}{c}{ Substrate } & \multicolumn{1}{c}{$\mathrm{k}_{\text {cat }}\left(\mathrm{s}^{-1}\right)$} & $\mathrm{K}_{\mathrm{m}}(\mu \mathrm{M})$ \\
\hline Penicillin G & $42.0 \pm$ & 0.3 & $5.9 \pm$ & 0.2 \\
Penicillin V & $8.1 \pm 2.7$ & $80 \pm$ & 8 \\
Cephalexin & 57 & \pm 1 & $1.2 \times 10^{3} \pm$ & 112 \\
Phenylacetic acid methyl ester & 190 & \pm 15 & $156 \pm$ & 8 \\
Phenylacetamide & 50 & \pm 4 & $200 \pm 10$ \\
\hline
\end{tabular}


TABLE 3

Kinetic Parameters for Chromogenic and Invisible Substrates Obtained with Progress Curve Analysis Using Periplasmic Extracts with Different Enzymes

\begin{tabular}{lccc}
\hline \multicolumn{1}{c}{ Constant } & E. coli & A. faecalis & \\
\hline $\mathrm{K}_{\text {cat }}^{\mathrm{b}}\left(\mathrm{s}^{-1}\right)$ & $18.0 \pm 0.2(16)$ & $47.7 \pm 2(50-95)$ & $11.2 \pm 0.3(27)$ \\
$\mathrm{K}_{m}^{\text {NIPAB }}(\mu \mathrm{M})$ & $16.2 \pm 0.8(20)$ & $4.2 \pm 2(5)$ & $11.6 \pm 2(11)$ \\
$\mathrm{k}_{\mathrm{cat}}^{\text {Pen }}\left(\mathrm{s}^{-1}\right)$ & $36.2 \pm 0.2(48)$ & $42 \pm 1(54)$ & $35 \pm 1.5(56)$ \\
$\mathrm{K}_{m}^{\text {PenG }}(\mu \mathrm{M})$ & $9.3 \pm 0.2(5)$ & $2.1 \pm 1.1(2)$ & $8.9 \pm 0.8(18)$ \\
$\mathrm{K}_{\mathrm{i}}^{\text {PAA }}(\mu \mathrm{M})$ & $72 \pm 3$ & $15 \pm 1(16)$ & $63 \pm 9$ \\
\hline
\end{tabular}

Note Values in parentheses denote literature values.

${ }^{a}$ Literature values taken from Refs. (10) and (20).

${ }^{\mathrm{b}}$ Literature values taken from Refs. (4) and (14).

' Literature values taken from Refs. (18) and (19).

lases from different organisms having different kinetic properties, the kinetics of acylases from E. coli ATCC 11105, A. faecalis, and K. citrophila were studied using periplasmic extracts. Progress curves were recorded for the hydrolysis of NIPAB in the presence of various amounts of invisible substrates and inhibitors. Accurate kinetic constants were obtained for the three different acylases (Table 3). All three acylases have similar kinetic parameters for the hydrolysis of NIPAB and penicillin G. However the penicillin acylase of A. faecalis has a higher specificity constant $\left(\mathrm{k}_{\text {cat }} / \mathrm{K}_{\mathrm{m}}\right)$ for both NIPAB and penicillin G, mainly caused by a higher affinity for the substrates compared to the $\mathrm{E}$. coli and the K. citrophila enzyme. The affinity of the A. faecalis enzyme for phenylacetic acid is also higher than that of the E. coli acylase. For K. citrophila kinetic constants were found which arealmost the same as the values for the $\mathrm{E}$. coli enzyme, which is in agreement with observations from Roa et al. (19, 20). The values obtained with the $\mathrm{E}$. coli periplasmic extract agree well with the values obtained with the pure enzyme, indicating that components present in the periplasmic extract do not interfere with the measurements.

\section{New Chromogenic Substrates}

For determining the kinetic parameters for the invisible substrates, the rate of conversion of these substrates should be higher than that of the chromogenic substrate. When both substrates are present in the reaction mixture, the relative rates at which the chromogenic substrate $\left(V_{\text {chrom }}\right)$ and the invisible substrate $\left(\mathrm{V}_{\text {invis }}\right)$ are converted are given by $\mathrm{Eq}$. [7] (11):

$$
\frac{\mathrm{V}_{\text {chrom }}}{\mathrm{V}_{\text {invis }}}=\frac{\left(\mathrm{K}_{\text {cat }} / \mathrm{K}_{\mathrm{m}}\right)_{\text {chrom }}}{\left(\mathrm{K}_{\text {cat }} / \mathrm{K}_{\mathrm{m}}\right)_{\text {invis }}} \cdot \frac{\left[\mathrm{S}_{\text {chrom }}\right]}{\left[\mathrm{S}_{\text {invis }}\right]}
$$

Due to the high $\mathrm{k}_{\mathrm{cat}} / \mathrm{K}_{\mathrm{m}}$ value, NIPAB is a poor reference substrate for studying invisible substrates which
TABLE 4

Kinetic Parameters and Inhibition Constants of the Product for Different Chromogenic Substrates of E. coli Penicillin Acylase

\begin{tabular}{lccl}
\hline Substrate & $\mathrm{K}_{\text {cat }}\left(\mathrm{s}^{-1}\right)$ & $\mathrm{K}_{\mathrm{m}}(\mu \mathrm{M})$ & $\mathrm{K}_{\mathrm{i}}(\mu \mathrm{M})$ \\
\hline NIPAB & 15 & 12 & 55 \\
NIPGB & 12 & $1.2 \times 10^{3}$ & $>2.5 \times 10^{4}$ \\
NIPOAB & 0.12 & 8 & 40 \\
\hline
\end{tabular}

are converted slowly. To find chromogenic substrates with lower $\mathrm{k}_{\text {cat }} / \mathrm{K}_{\mathrm{m}}$ values to study slowly converted substrates, we determined the kinetic parameters for NIPAB analogs in which the phenylacetic acid moiety was replaced by a D-phenylglycine or a phenoxyacetic acid group, yielding D-2-nitro-5-[(phenylglycyl)amino]benzoic acid (NIPGB) and 2-nitro-5-[(phenoxyacetyl)amino]benzoic acid (NIPOAB), respectively (Fig. 1).

Both NIPGB and NIPOAB were converted by penicillin acylase of $\mathrm{E}$. coli with $\mathrm{K}_{\text {cat }} / \mathrm{K}_{\mathrm{m}}$ values which are significantly lower than the value for NIPAB (Table 4) and could therefore be used to determine the kinetic parameters for cephalexin and penicillin V, respectively (Table 2). The progress curves which were obtained when NIPGB was used to study the conversion of $25 \mathrm{mM}$ cephalexin could be fitted only when an inhibition constant of 7-aminodesacetoxycephalosporanic acid (7-ADCA), the product of cephalexin hydrolysis, of $7.5 \mathrm{mM}$ was included (Fig. 4). This value is in agreement with the inhibition constant obtained in independent experiments (Alkema, manuscript in preparation). The $\mathrm{k}_{\text {cat }}$ and $\mathrm{K}_{\mathrm{m}}$ values that were obtained for cephalexin are similar to literature values

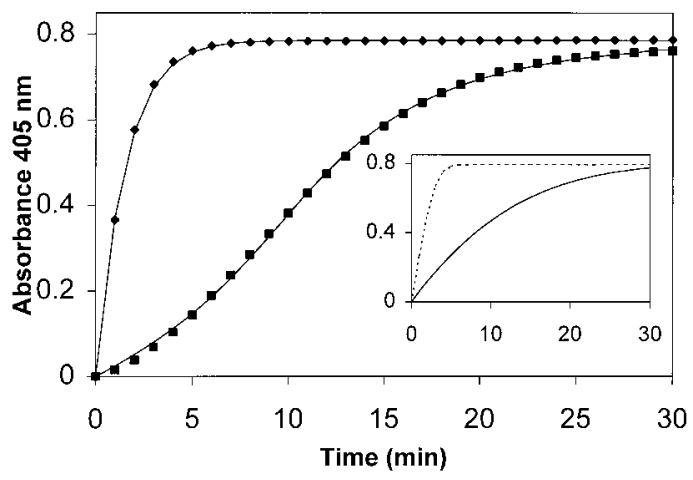

FIG. 4. Effect of cephalexin on the hydrolysis of NIPGB and NIPAB. Symbols: $(\diamond)$ hydrolysis of $86 \mu \mathrm{M}$ NIPGB without cephalexin, and ( $\mathbf{\square})$ hydrolysis of $86 \mu \mathrm{M}$ NIPGB with $25 \mathrm{mM}$ cephalexin. Symbols denote experimental data; the line shows the fit with the following parameters: $\mathrm{k}_{\mathrm{cat}}^{\mathrm{NIPB}}=11 \mathrm{~s}^{-1}, \mathrm{~K}_{\mathrm{m}}^{\mathrm{NIPGB}}=1 \mathrm{mM}, \mathrm{k}_{\text {cat }}^{\text {cephalexin }}=57$ $\mathrm{s}^{-1}, \mathrm{~K}_{\mathrm{m}}^{\text {cephalexin }}=1.25 \mathrm{mM}, \mathrm{K}_{\mathrm{i}}^{\mathrm{ADCA}}=7.5 \mathrm{mM}$. The inset shows similar traces with NIPAB as the chromogenic substrate: (- - ) hydrolysis of NIPAB without cephalexin and (-) hydrolysis of NIPAB with $25 \mathrm{mM}$ cephalexin. 
(9). The preferential conversion of cephalexin in the presence of $86 \mu \mathrm{M}$ NIPGB caused a typical S-shaped progress curve, which was not observed when $100 \mu \mathrm{M}$ NIPAB was the reference substrate, since only a small amount of the cephalexin was hydrolyzed under the latter conditions (Fig. 4).

\section{DISCUSSION}

Although NIPAB and analogous spectroscopic substrates have been used in screening procedures for acylase activities in microorganisms $(13,16-18)$ and in $\mathrm{ki}$ netic studies $(4,19,20)$, their use for determination of kinetic parameters for the conversion of invisible substrates has not been described. With the method reported here, steady-state kinetic constants for invisible substrates, induding inhibition constants of the product, can be obtained by measuring the effect on the time course of hydrolysis of a chromogenic reference substrate. The method is convenient because no detection methods need to be developed for each invisible compound. Furthermore, fewer reactions must be carried out than with initial rate measurements. Another advantage is that product inhibition which may have a large effect on the outcome of initial rate measurements can be included in the model describing the reactions.

The kinetic values obtained with the E. coli penicillin acylase for the hydrolysis of NIPAB and penicillin G agree well with values obtained in literature $(9,14)$. The $\mathrm{k}_{\text {cat }}$ value of $170 \mathrm{~s}^{-1}$ reported for the hydrolysis of phenylacetic acid ethyl ester (9) is comparable to the value of $190 \mathrm{~s}^{-1}$ that was obtained for phenylacetic acid methyl ester and indicates that phenylacetylated esters are good substrates for penicillin acylase. A lower value was found for the $k_{\text {cat }}$ for phenylacetamide, which can be explained by the fact that amide bonds are in general less reactive than ester bonds. The higher rate observed with the ester also indicates that cleavage of the covalent intermediate occurs at a rate of at least $190 \mathrm{~s}^{-1}$ and thus is not the rate-limiting step in the catalytic cycle with the amide.

Using the method reported here, acylases from different organisms could be characterized. The kinetic constants of the enzyme from A. faecal is for penicillin $G$ and phenylacetic acid and the $K_{m}$ value for NIPAB are in agreement with values reported earlier $(3,15)$, although Svedas et al. reported a somewhat higher $\mathrm{k}_{\text {cat }}$ for NIPAB (4). The differences observed among the values found for the penicillin acylase of $\mathrm{K}$. citrophila might be caused by the different experimental setup with respect to $\mathrm{pH}$ and acetonitrile concentration. In general, however, these results show that the method that was used allows rapid characterization of acylases and is accurate enough to discriminate among similar acylases from different organisms having different substrate specificities.
The method is only suitable for measuring the kinetics of conversion of an invisible substrate if the $K_{i}$ of the hydrolysis product is different from the substrate $K_{m}$. In the case that both constants are equal, no change in inhibition of NIPAB hydrolysis can be observed upon conversion of the invisiblesubstrate. However, for almost all substrates of penicillin acylase studied thus far, a difference between the binding constants of the substrate and the hydrolysis product of about a factor 5 or more was observed which was sufficient to observe the conversion of the invisible substrate.

Another important aspect is the fact that the $\mathrm{k}_{\text {cat }} / \mathrm{K}_{\mathrm{m}}$ value for the chromogenic substrate should be lower than the $\mathrm{k}_{\text {cat }} / \mathrm{K}_{\mathrm{m}}$ value for the invisible substrate to obtain complete or significant conversion of the invisible substrate during the course of the reaction. The range in $\mathrm{K}_{\text {cat }} / \mathrm{K}_{\mathrm{m}}$ values of penicillin acylase for phenylacetylated, phenoxyacetylated and phenylglycylated chromogenic substrates was sufficient to determine kinetic parameters for several substrates of interest. An advantage of phenylglycylated chromogenic substrates is that the phenylglycine, which is produced during hydrolysis of these compounds, does not significantly inhibit the enzyme, making the analysis of progress curves less complicated.

The method using chromogenic reference substrates is useful for rapid screening of mutants with respect to their kinetic parameters for $\beta$-lactam antibiotics and the related precursor substrates. Chromogenic substrates have been used in screening protocols (21), to study substrate specificities of esterases (22), phosphatases (23), dehydrogenases (24), and peptidases (25). The method described in this paper should also be applicable to obtain kinetic parameters for the conversion of invisible substrates by those enzymes.

\section{ACKNO WLEDG MENT}

We thank Dr. E. de Vries for synthesizing NIPOAB.

\section{REFERENCES}

1. Cole, M. (1969) Biochem. J . 115, 733-739.

2. Baker, W. L. (1983) Antimicrob. Agents Chemother. 23, 26-30.

3. Balasingham, K., Warburton, D., Dunnill, P., and Lilly, M. D. (1972) Biochim. Biophys. Acta 276, 250-256.

4. Svedas, V., Guranda, D., Van Langen, L., Van Rantwijk, F., and Sheldon, R. (1997) FEBS Lett. 417, 414-418.

5. Page, M. I. (1992) in The Chemistry of $\beta$-Lactams (Page, M. I., Ed.), pp. 79-99, Blackie Academic \& Professional, London.

6. Ho, L. Y., and Humphrey, A. E. (1970) Biotechnol. Bioeng. 12, 291-311.

7. Szewczuk, A., Siewiński, M., and Słowińska, R. (1980) Anal. Biochem. 103, 166-169.

8. Kutzbach, C., and Rauenbusch, E. (1974) HoppeS. Z. Physiol. Chem. 355, 45-53.

9. Margolin, A. L., Svedas, V. K., and Berezin, I. V. (1980) Biochim. Biophys. Acta 616, 283-289. 
10. Veronese, F., Franchi, D., Boccu, E., Guerrato, A., and Orsolini, P. (1981) II Farmaco Ed. Sc. 36(7), 663- 670.

11. Cornish-Bowden, A. (1995) Fundamentals of Enzyme Kinetics. Portland Press, London.

12. Sambrook, J ., Fritsch, E. F., and Maniatis, T. (1989) Molecular Cloning: A Laboratory Manual. Cold Spring Harbor Laboratory Press, Cold Spring Harbor, NY.

13. Kerr, D. E. (1993) Anal. Biochem. 209, 332-334.

14. Kasche, V., Haß, W., Niebuhr-Redder, C., and Piotrascke, E. (1992) BioEngineering 2(8), 69-77.

15. Verhaert, R. M. D., Riemens, A. M., Van der Laan, J -M., Van Duin, J ., and Quax, W. J . (1997) Appl. Environ. Microbiol. 63, 3412-3418.

16. Zhang, Q., Zhang, L., Han, H., and Zhang, Y. (1986) Anal. Biochem. 156, 413- 416.

17. Zhang, Q., Xu, W., and Shi, L. (1991) Anal. Biochem. 196, 201-206.
18. Bouvrette, P., and Ziomek, E. (1992) Anal. Biochem. 200, 315320.

19. Roa, A., Castillón, M. P., Goble, M. L., Virden, R., and García, J . L. (1995) Biochem. Biophys. Res. Commun. 206, 629- 635.

20. Roa, A., Goble, M. L., Garcia, J . L., Acebal, C., and Virden, R. (1996) Biochem. J . 316, 409- 412.

21. Manafi, M., Kneifel, W., and Bascomb, S. (1991) Microbiol. Rev. 55, 335-348.

22. Li, J ., Szittner, R., Derewenda, Z. S., and Meighen, E. A. (1996) Biochemistry 35, 9967-9973.

23. Evans, B., Tishmack, P. A., Pokalsky, C., Zhang, M., and Van Etten, R. L. (1996) Biochemistry 35, 13609-13617.

24. Kitson, T. M., and Kitson, K. E. (1996) Biochem. J . 316, 225232.

25. Nienaber, V. L., Mersinger, L. J ., and Kettner, C. A. (1996) Biochemistry 35, 9690-9699. 